\title{
Sustained ERK1/2 signaling is necessary for follicular rupture during ovulation in mice
}

\author{
Ejimedo Madogwe®1, Yasmin Schuermann', Dayananda Siddappa', Vilceu Bordignon', \\ Philippe P Roux ${ }^{2}$ and Raj Duggavathi ${ }^{1}$ \\ ${ }^{1}$ Department of Animal Science, McGill University, Sainte-Anne-de-Bellevue, Quebec, Canada and ${ }^{2}$ Institute for \\ Research in Immunology and Cancer, Université de Montréal, Montreal, Quebec, Canada \\ Correspondence should be addressed to R Duggavathi; Email: raj.duggavathi@mcgill.ca
}

\begin{abstract}
Abolition of the LH-induced ERK1/2 pathway leads to dramatic changes in gene expression in granulosa cells, subsequently abrogating ovulation. Here we explored whether sustained ERK1/2 signaling beyond immediate-early hours of the LH surge is important for ovulation in mice. First, we examined the effect of inhibition of ERK1/2 activity at $4 \mathrm{~h}$ after hCG stimulation on ovulation in superovulated immature mice. Treatment with the ERK1/2 pathway inhibitor PD0325901 at $4 \mathrm{~h}$ post-hCG disrupted follicular rupture without altering cumulus expansion, oocyte meiotic maturation and luteinization. Profiling the expression pattern of genes of the RSK family of ERK1/2 signal mediators revealed that RSK3, but not other isoforms, was induced by hCG treatment. Further, RSK3-knockout mice were sub-fertile with reduced ovulation rate and smaller litter size compared to WT mice. Given that PD0325901 inhibits all mediators of ERK1/2 signaling, we chose to evaluate the gene expression underlying deficient follicular rupture in ERK1/2 inhibited mice. We found that inhibition of ERK1/2 signaling at $4 \mathrm{~h}$ post-hCG resulted in an imbalance in the expression of genes involved in extracellular matrix degradation and leukocyte infiltration necessary for follicular rupture. In conclusion, our data demonstrate that sustained ERK1/2 signaling during ovulation is not required for cumulus expansion, oocyte meiotic maturation and luteinization, but is required for follicular rupture.

Reproduction (2021) 161 183-193
\end{abstract}

\section{Introduction}

Ovulation is a unique biological event, which is essential for reproductive success in all mammals. It is a prolonged process $(12-16 \mathrm{~h}$ in mice and $36-40$ $\mathrm{h}$ in primates) involving multiple events including oocyte maturation, luteinization and follicular rupture. The single trigger for the initiation of ovulation is the preovulatory surge of luteinizing hormone $(\mathrm{LH})$ from the pituitary. Acting through its receptors (Lhcgr), LH triggers multiple signaling pathways (Richards 2005). Some of the important signaling pathways through which LH brings about ovulatory events are CAMP/PKA pathway, ERK1/2 pathway and PI3K-Akt pathway (Park et al. 2004, Ashkenazi et al. 2005, Fan et al. 2008, BenAmi et al. 2009). These signaling pathways initiate an intricate gene expression program that underpins oocyte maturation, follicular rupture and luteinization.

Signals from extracellular signal-regulated kinases 1 and $2($ ERK1/2) are mediated through multiple proteins both in the cytoplasm and the nucleus. Among the cytoplasmic targets of ERK1/2 are the $90 \mathrm{kDa}$ ribosomal S6 kinases (RSKs), which belong to the family of serine/ threonine kinases (Anjum \& Blenis 2008). In mice and humans, there are four isoforms of RSKs (RSK1, 2, 3 and
4), encoded by four genes Rps6ka1, Rps6ka3, Rps6ka2 and Rps6ka6, respectively (Kim et al. 2006, Anjum \& Blenis 2008). Abolition of the LH-induced ERK $1 / 2$ pathway leads to dramatic changes in gene expression in granulosa cells, subsequently abrogating ovulation (Fan et al. 2009, Siddappa et al. 2015). However, these studies inherently tested the role of ERK $1 / 2$ signaling as part of the immediate-early response to $\mathrm{LH}$ surge by abrogating ERK1/2 signal prior to the LH surge. One of the important mediators of ERK1/2 signals, RSK3 (Rps6ka2), was shown to be induced in granulosa cells by the LH surge (Fan et al. 2009). This indicates that ERK $1 / 2$ signals may continue to be activated by the mediators that become available later during the ovulatory process. Consistent with this, RPS6KA2 expression in human cumulus cells was shown to be associated with a higher quality of embryos (Adriaenssens et al. 2010). Therefore, it is possible that the lingering ERK1/2 signals may play important roles in the later processes of ovulation. We hypothesized that the continued ERK1/2 signaling beyond immediate-early hours of LH surge is important for ovulation in mice. To test this hypothesis, we inhibited periovulatory ERK $1 / 2$ signaling by administering the pharmacological inhibitor, PD0325901, $4 \mathrm{~h}$ after hCG stimulation in superovulated immature mice. We also examined the role of the 
ERK1/2 mediator, RSK3, in ovulation and fertility using RSK3-knockout mice (Li et al. 2013). Here we show that sustained ERK1/2 signaling later during the ovulatory process regulates follicular rupture.

\section{Materials and methods}

\section{Animal model}

For studies involving ERK1/2 inhibitor treatment, we used immature superovulated $\mathrm{C} 57 \mathrm{BL} / 6 \mathrm{NCrl}$ mice (Charles River) to investigate the effect of the abolition of ERK1/2 signaling $4 \mathrm{~h}$ after hCG stimulus on ovulation. We chose this model because the immature superstimulated mouse model offers an investigation of granular time-specific ovarian processes, which is not possible in adult mice. The animal use protocol for the use of $\mathrm{C} 57 \mathrm{BL} / 6 \mathrm{NCrl}$ mice in these experiments was approved by the Facility Animal Care and Use Committee of McGill University.

We also used WT (RSK3+/+) and global-knockout (RSK3-/-) mice, which have been previously described (Li et al. 2013), for studies investigating the role of RSK3 in the ovary. For these experiments, we used both immature (superovulation response) and adult (breeding and natural cycle) mice. The animal use protocol for the use of RSK3 WT and knockout mice was approved by the animal care committee of Université de Montréal.

For both sets of experiments, mice were housed in standard animal cages and provided water and feed (Rodent Diet, Harlan Teklad, Montreal, Canada) ad libitum. They were maintained under a $12 \mathrm{~h}$ light:12 h darkness cycle.

\section{Superovulation and sample collection}

Immature mice (23- to 25-day-old) were first treated with equine chorionic gonadotropin (eCG; Sigma Life Sciences; 5 IU i.p.) to stimulate follicle development. Forty-eight hours later, mice were treated with human chorionic gonadotropin (hCG; Sigma Life Sciences; 5 IU i.p.) to induce ovulation and luteinization. In this protocol, ovulation occurs at 12-14 h post-hCG (Richards et al. 2002, Duggavathi et al. 2008). Ovaries were collected from mice sacrificed with isoflurane and carbon dioxide followed by cervical dislocation in accordance with the approved standard operating procedure at specific time-points relative to superovulation treatment as described for each experiment. Granulosa cell, luteal cell and cumulus-oocyte-complex samples, when needed, were collected by follicular puncture using 27.5-gauge needles as described previously (Fan et al. 2011, Dupuis et al. 2014, Duggavathi et al. 2015). This method allows for the collection of pure populations of granulosa cells and enriched populations of luteal cells (Fan et al. 2011, Duggavathi et al. 2015) with the typical expression pattern of Cyp19a1, Star, Pgr and Bhmt (Supplementary Fig. 1, see section on supplementary materials given at the end of this article). These samples were either processed immediately or stored at $-80^{\circ} \mathrm{C}$ until further use.

\section{Inhibition of ERK1/2 activity}

We have used the Mp2k1/Mp2k2 (MEK1/2) inhibitor PD0325901 (Selleckchem, USA) previously to inhibit ERK1/2 activation in the ovary (Siddappa et al. 2015). A dosing solution of $2.5 \mu \mathrm{g} / \mu \mathrm{L}$ in $5 \%$ DMSO in saline was prepared just before treatment. For inhibition of ERK1/2 activity, mice were administered a single dose of PD0325901 (25 $\mu \mathrm{g} / \mathrm{g}$ body weight, i.p.) at $4 \mathrm{~h}$ after hCG stimulation. Mice treated with $5 \%$ DMSO in saline served as vehicle controls. We determined ERK $1 / 2$ activity by measuring the abundance of the phosphorylated isoform of ERK1/2 (at Thr202/Tyr204) relative to its total isoform. It has been previously established that PD0325901 is effective in inhibiting ERK1/2 phosphorylation within $1 \mathrm{~h}$ of treatment (Henderson et al. 2010, Siddappa et al. 2015). This inhibitory effect is reversible and appears to last for $8 \mathrm{~h}$ (our unpublished observation in mouse granulosa cells and in papillary thyroid carcinoma cells (Henderson et al. 2010) both in vitro and in vivo).

\section{Assessment of ovulation rate, oocyte maturation and ovarian histology in vehicle- and PD0325901-treated mice}

To test the effect of ERK $1 / 2$ inhibition at $4 \mathrm{~h}$ post-hCG, we collected oviducts from vehicle- to PD0325901-treated mice ( $n=7-10$ per group) at $18 \mathrm{~h}$ post-hCG to count the number of cumulus-oocyte complexes (COCs) ovulated. To evaluate the maturation status of oocytes ovulated, the COCs from four to five mice per group were denuded using hyaluronidase enzyme to remove cumulus cells from oocytes. These denuded oocytes were stained using DAPI and observed under a fluorescent microscope (Nikon) to evaluate oocyte meiotic maturation as determined by the presence of a polar body. For histological evaluation, ovaries collected at $18 \mathrm{~h}$ post-hCG from these mice were fixed in $10 \%$ neutral buffered formalin for at least 2 days. Ovaries were also frozen in liquid nitrogen and stored at $-80^{\circ} \mathrm{C}$ for protein extraction. For histology, ovaries from four to five mice per group were embedded in paraffin and were cut (4-5 $\mu \mathrm{m}$ thickness) using a rotatory microtome (Leica RM2125RT). Sections were stained by hematoxylin and eosin for histological observation under Leica DM200 microscope attached to a Leica EC3 camera.

\section{Reproductive phenotyping of RSK3-/- mice}

We first assessed the ovulation rate in immature superovulated mice and also in adult cyclic mice. Oviducts from immature superovulated RSK3+/+ and RSK3-/- ( $n=5-6$ per genotype) mice were collected at $18 \mathrm{~h}$ post-hCG to count the number of COCs ovulated. To assess ovulation rate in adult mice, post-pubertal knockout and WT females (8-9 weeks) were housed with $\mathrm{C} 57 \mathrm{BL} / 6 \mathrm{NCrl}$ proven males and inspected for vaginal plugs daily between 08:30 and 9:30 h. On the day when the vaginal plug was observed, confirming that mating had occurred, oviducts were collected from $R S K 3+/+$ and RSK3-/- females ( $n=4$ per genotype). A 27G needle was used to puncture oviducts and allow the oocytes to flow out so as to determine the number of ovulations. Finally, fertility was assessed by mating $\mathrm{C} 57 \mathrm{BL} / 6 \mathrm{NCrl}$ proven males with female RSK3-/- mice $(n=4)$ or RSK3+/+ mice $(n=4)$ for 6 months. 
The frequency and number of pups per litter were noted for each female.

\section{Quantitative RT PCR}

Total RNA was purified from granulosa cells or isolated ovulating follicles (described in 'Results' section) using the Direct-zol RNA miniprep isolation kit from Zymo Research (R2050). The quality and quantity of RNA were evaluated using the Nanodrop 2000 (Thermo Scientific), followed by cDNA synthesis from $250 \mathrm{ng}$ of total RNA using the iScript cDNA Synthesis kit (BioRad). qPCR assays to determine relative mRNA abundance were conducted on CFX384 (BioRad) with diluted cDNA samples. The succeeding conditions were performed by CFX384: an initial denaturation of $95^{\circ} \mathrm{C}$ for $5 \mathrm{~min}$ followed by 39 cycles of $95^{\circ} \mathrm{C}$ for $15 \mathrm{~s}, 58^{\circ} \mathrm{C}$ for 30 $\mathrm{s}$ for annealing and $95^{\circ} \mathrm{C}$ for $10 \mathrm{~s}$. The primers used for the experiments, with efficiencies ranging from 90 to $110 \%$ and a correlation coefficient of 0.95-1.00, are given in Table 1. Transcript abundance was normalized to four control genes (B2m, Gapdh, L19 and Sdha).

\section{PCR arrays}

We performed three PCR arrays using RNA isolated from ovulating follicles of superovulated immature mice treated with PD0325901 and vehicle ( $n=3$ mice per group). Each plate had samples from one vehicle and one inhibitor-treated mice. Ovaries were collected at $8 \mathrm{~h}$ after hCG stimulation and two follicles were isolated per mouse ( 1 follicle per ovary). Next, we purified RNA from these two follicles and carried out cDNA synthesis using the $\mathrm{RT}^{2}$ First-strand Kit (Qiagen \#330401) to synthesize cDNA from $400 \mathrm{ng}$ of total RNA. We ran the $\mathrm{RT}^{2}$ Wound Healing Profiler PCR Array (Qiagen \#330231 PAMM1212E-4) with 84 genes (associated with tissue remodeling and leukocyte infiltration), 5 reference genes and 7 proprietary controls to monitor genomic DNA contamination, first-strand synthesis and real-time PCR efficiency. We chose the Wound Healing array as it contains genes involved in both tissue remodeling (e.g. Actc1, Col1a1 and (tsl) and leukocyte infiltration (e.g. Ccl7, Cxcl11 and Fgf2). The array was performed according to the manufacturer's instructions. Briefly, we prepared the PCR components in a loading reservoir and added $10 \mu \mathrm{L}$ of mix to each well using a multichannel pipette and EZ load covers (included in the kit). We ran the recommended qPCR program of 1 cycle for 10 min at $95^{\circ} \mathrm{C}, 40$ cycles of $15 \mathrm{~s}$ at $60^{\circ} \mathrm{C}$ and $1 \mathrm{~min}$ at $60^{\circ} \mathrm{C}$. We also ran a dissociation (melting) curve analysis to verify PCR specificity. The threshold cycle $(\mathrm{Cq})$ values were transferred to a blank excel sheet, formatted, and uploaded to the Qiagen website for analysis. We then performed qPCR to confirm the differentially expressed genes from the PCR arrays.

\section{Protein extraction and immunoblotting}

Total protein was extracted from either a pure population of granulosa cells collected at $8 \mathrm{~h}$ post-hCG (for ERK1/2 pathway evaluation) or whole ovaries collected at $18 \mathrm{~h}$ post-hCG (for quantifying Star abundance). Samples were homogenized in total extract lysis buffer $(25 \mathrm{mM}$ Tris- $\mathrm{HCl} \mathrm{pH} 7.5,5 \mathrm{mM}$ $\mathrm{MgCl}_{2}, 10 \%$ glycerol, $100 \mathrm{mM} \mathrm{NaCl}, 0.01 \%$ NP-40, 500 $\mu \mathrm{M}$ dithiothreitol and distilled water) with freshly added $1 \%$ protease and phosphatase inhibitors (G Biosciences, St. Louis, $\mathrm{MO}$, USA) and stored at $-80^{\circ} \mathrm{C}$ until further use. At the time of immunoblotting, 5\% Laemmli solution was added to each sample, which was subsequently boiled at $95^{\circ} \mathrm{C}$ for $5 \mathrm{~min}$. A $10 \%$ SDS-PAGE gel was used to separate proteins by electrophoresis and then transferred onto a nitrocellulose membrane followed by blocking in $5 \%$ milk in Tris-buffered saline with $0.1 \%$ Tween20 (TBS-T) at room temperature. Membranes were incubated overnight at $4{ }^{\circ} \mathrm{C}$ with primary antibodies against: phosphoERK1/2 (Thr202/Tyr204; \#4376, Cell Signaling, dilution of $1: 1000)$, total-ERK1/2 (\#4695, Cell Signaling, 1:1000), Star (\#sc-25806, Santa Cruz, 1:500) and beta-actin (Actb; ab8227, Abcam, 1:10 000). Membranes were washed three times for $10 \mathrm{~min}$ in TBST before and after incubation with secondary antibody goat anti-rabbit-lgG (1:10000, \#ab6721, Abcam) for $1.5 \mathrm{~h}$ at room temperature. The Immun-Star Western Chemiluminescent Kit (Bio-Rad) and Chemidoc Analyzer

Table 1 Primer sequences used in RT-PCR.

\begin{tabular}{|c|c|c|}
\hline Gene & Forward primer & Reverse primer \\
\hline Actc1 & CTGGATTCTGGCGATGGTGTA & CGGACAATTTCACGTTCAGCA \\
\hline Adamts 10 & GGCTGGGCCTCACATTCAA & GAAGGCAATCTCATAGСTCTCC \\
\hline$B 2 m$ & TTCTGGTGCTTGTCTCACTGA & CAGTATGTTCGGCTTCCCATTC \\
\hline $\mathrm{Cc} / 12$ & АTTTCСАСАСТTСТАТGССТССТ & ATCCAGTATGGTCCTGAAGATCA \\
\hline Ccl7 & GCTGCTTTCAGCATCCAAGTG & CCAGGGACACCGACTACTG \\
\hline $\mathrm{CxCl1}$ & CTGGGATTCACCTCAAGAACATC & CAGGGTCAAGGCAAGCCTC \\
\hline Gapdh & AGGTCGGTGTGAACGGATTTG & TGTAGACCATGTAGTTGAGGTCA \\
\hline$\angle 19$ & ATGAGTATGCTCAGGCTACAGA & GCATTGGCGATTTCATTGGTC \\
\hline Mmp11 & CCGGAGAGTCACCGTCATC & GCAGGACTAGGGACCCAATG \\
\hline Rps6ka1 & CCATCACACACCACGTCAAG & TTGCGTACCAGGAAGACTTTG \\
\hline Rps6ka2 & GCAGGTTCTTCTCCGTGTACC & GAGGGGTCTGССТTСТСАAА \\
\hline Rps6ka3 & ATGGATGAACCTATGGGAGAGG & AAGCTGTCTAGCATCAGAGCC \\
\hline Rps6ka6 & CGCCATCAGCCAAACTCAGAT & ATGTTCGCTTTTTCATGTTCCG \\
\hline Sdha & GGAACACTCCAAAAACAGACCT & CCACCACTGGGTATTGAGTAGAA \\
\hline Timp 1 & GCAACTCGGACCTGGTCATAA & CGGCCCGTGATGAGAAACT \\
\hline Timp2 & TCAGAGCCAAAGCAGTGAGC & GCCGTGTAGATAAACTCGATGTC \\
\hline
\end{tabular}


A

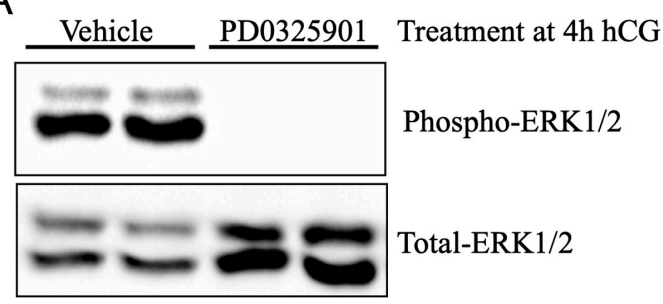

Granulosa cells at $7 \mathrm{~h} \mathrm{hCG}$
B

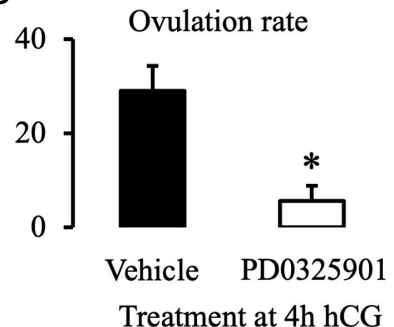

C

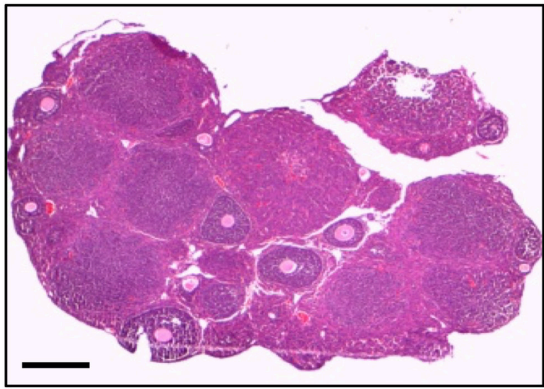

Vehicle

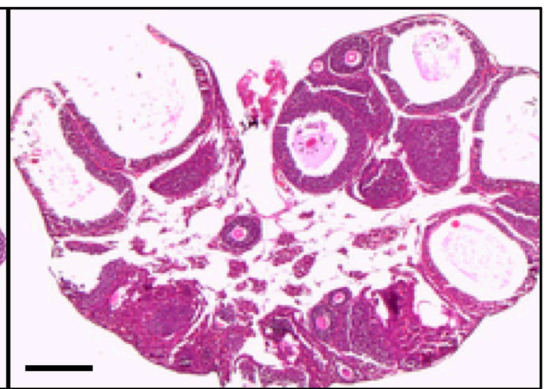

PD0325901
Figure 1 Inhibition of ERK1/2 at $4 \mathrm{~h}$ post-hCG results in reduced ovulation rate. (A) Transient inhibition of hCG-induced ERK1/2 activity by PD0325901 treatment. Granulosa cells from mice treated with PD0325901 at $4 \mathrm{~h}$ after hCG administration were collected at $7 \mathrm{~h}$ after hCG treatment and showed the absence of phosphorylation of ERK1/2 at Thr202/Tyr204 compared to vehicle-treated mice. $n=2$ mice/ group. (B) Treatment of immature mice with a single dose of $25 \mu \mathrm{g} / \mathrm{g}$ of PD0325901 at $4 \mathrm{~h}$ hCG reduced the ovulation rate compared to vehicle-treated mice during superovulation (vehicle control $n=7$ mice, PD0325901 $n=$ 10 mice). $*$ Significant difference between the two groups $(P<0.05)$. (C) Histology of the ovaries collected at $18 \mathrm{~h}$ after hCG from PD0325901 or vehicle-treated mice. Paraffin embedded ovaries were sectioned to 4-5 $\mu \mathrm{m}$ thickness and stained with hematoxylin and eosin. Numerous corpora lutea were observed in ovaries collected from mice which were treated with vehicle. Ovaries from PD0325901-treated mice showed distended unruptured preovulatory follicles with reduced number of corpus luteum compared to vehicle-treated mice. Scale bars at $200 \mu \mathrm{m}$. were used to detect immunoblotted proteins. Densitometry of the protein bands was measured using ImageLab software. For measurement of ERK1/2 activity, the membranes were first blotted with the phospho-ERK1/2 antibody and following its readout, the membranes were stripped using stripping buffer (10\% SDS - 20 mL, 0.5 M Tris- $\mathrm{HCl}$, pH 6.8 - $12.5 \mathrm{~mL}$, DEPC $\mathrm{H} 2 \mathrm{O}-67.5 \mathrm{~mL}$ and 2-mercaptoethanol $-0.8 \mathrm{~mL}$ ) and reblotted with the total-ERK1/2 antibody.

\section{Statistical analysis}

Ovulation data and mRNA abundance data were expressed as mean \pm S.E.M. and analyses were performed using SigmaPlot 12.3 Software, San Jose, CA, USA. The data were checked for normality by the Shapiro-Wilke test and analyzed via the unpaired Student's $t$-test. Data involving more than one-time point were analyzed by one-way ANOVA. A significance level of $P<0.05$ was used for statistical inference.

\section{Results \\ PD0325901 treatment at $4 \mathrm{~h}$ post-hCG inhibits ERK1/2 activity in granulosa cells}

We have previously demonstrated that PD0325901 pretreatment $2 \mathrm{~h}$ before hCG stimulus inhibits immediateearly ERK1/2 activity in granulosa cells leading to anovulation (Siddappa et al. 2015). In the present study, we wanted to test if PD0325901 at $4 \mathrm{~h}$ after hCG treatment impacts ovulation in mice. First, we examined if this treatment resulted in inactivation of ERK1/2 signaling as measured by phospho-ERK1/2 levels in purified granulosa cells at $8 \mathrm{~h}$ post-hCG (Fig. 1A).

\section{PD0325901 treatment at $4 \mathrm{~h}$ post-hCG inhibits follicular rupture without altering oocyte maturation and luteinization}

In our previous study, we showed that inhibition of ERK $1 / 2$ activity at $2 \mathrm{~h}$ before hCG treatment resulted in anovulation with trapped oocytes within large antral follicles. The oocytes within these non-luteinized follicles were in germinal vesicle (GV) stage indicating failure of meiotic resumption and cumulus cells failed to undergo expansion. In the current study, we found that inhibition of ERK $1 / 2$ activity $4 \mathrm{~h}$ after the LH surge dramatically reduced the ovulation rate $(P<0.05)$ compared to vehicle-treated mice (Fig. 1B). Histologically, the ovaries of vehicle-treated mice showed numerous well-developed corpora lutea (Fig. 1C). Conversely, the ovaries of PD0325901-treated mice showed numerous distended unruptured preovulatory follicles with sporadic corpora lutea compared to vehicletreated mice (Fig. 1C). Upon close observation, cumulus expansion was evident in follicles of PD0325901-treated mice (Fig. 2A). This observation was not quantified as we did not encounter unruptured follicles in vehicle-treated mice at $18 \mathrm{~h}$ post-hCG. Because some of the oocytes in histological sections of PD0325901-treated mice showed polar bodies (Fig. 2A), we also examined the ovulated oocytes collected from the oviducts in both vehicle- and PD0325901-treated mice for meiotic resumption. Polar bodies, indicative of metaphase II, were evident upon DAPI staining of ovulated oocytes in PD0325901-treated mice, similar to those of vehicle-treated mice (Fig. 2B and C). These qualitative but robust observations demonstrated that inhibition of ERK1/2 at $4 \mathrm{~h}$ post-hCG did not affect oocyte maturation. 

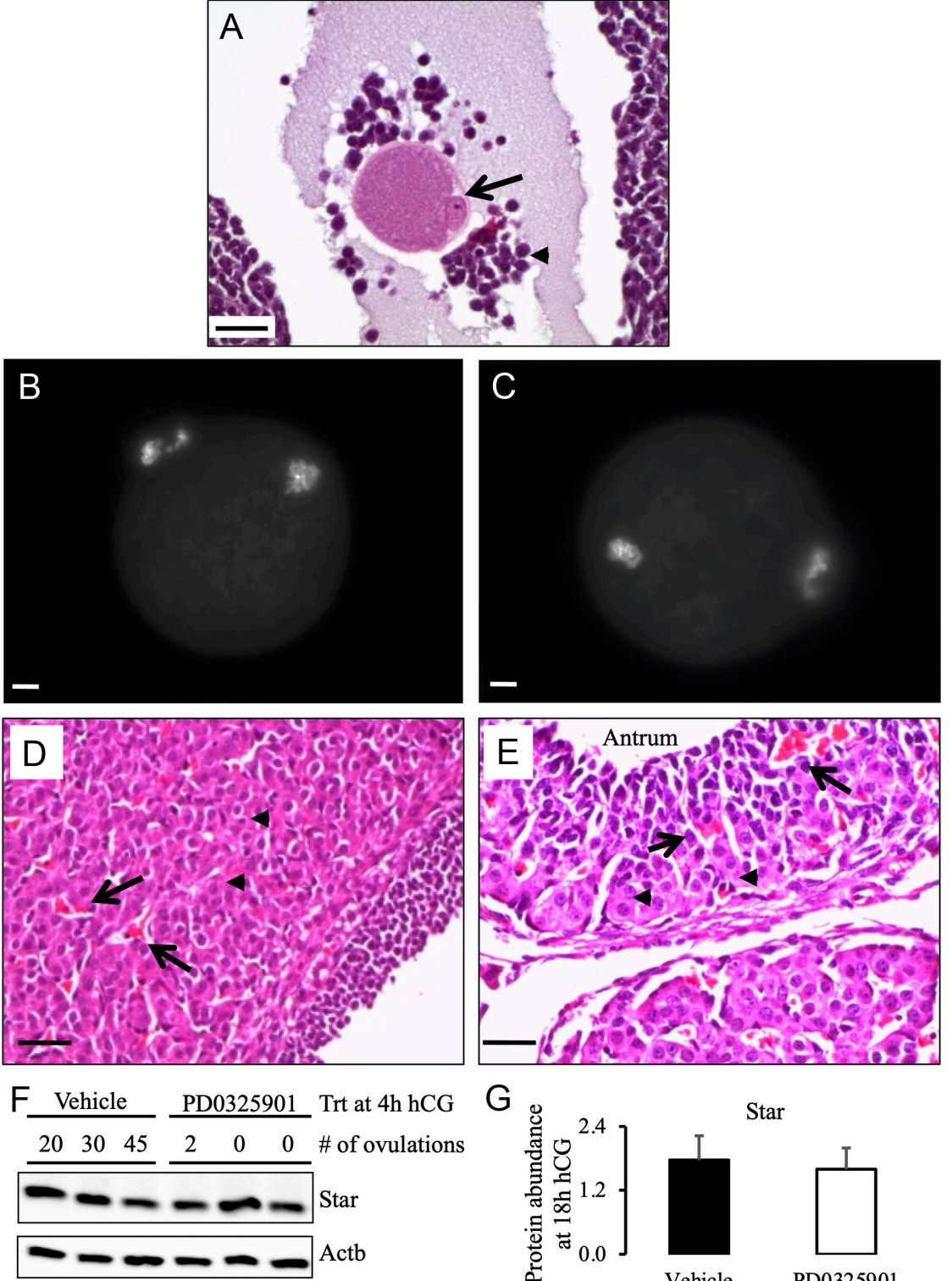

Whole ovaries at $18 \mathrm{~h} \mathrm{hCG}$
$\mathrm{G}$

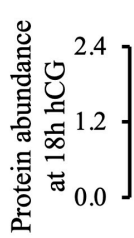
Star
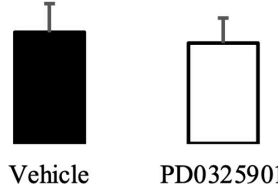

Treatment at $4 \mathrm{~h} \mathrm{hCG}$
Figure 2 Inhibition of ERK1/2 at 4 h post-hCG disrupts follicular rupture without affecting cumulus expansion, oocyte maturation and luteinization. (A) The hematoxylin/eosin stained sections of the ovaries from PD0325901-treated mice were evaluated. Metaphase II oocyte that was trapped inside the unruptured follicle showing extruded polar body (arrow) indicating unaltered oocyte maturation. Trapped cumulus-oocyte complexes inside the unruptured follicles showed normal cumulus expansion (arrowhead). Mice were administered with PD0325901 at $4 \mathrm{~h}$ hCG during superovulation and ovaries were collected at $18 \mathrm{~h}$ after hCG. Scale bar at $100 \mu \mathrm{m}$. (B and C) Oocytes collected from oviducts at $18 \mathrm{~h}$ after hCG were stained with DAPI and evaluated for meiotic maturation. Metaphase II oocytes with extruded polar body in vehicle control mice and PD0325901-treated mice, respectively. COCs were collected from the oviduct at $18 \mathrm{~h}$ hCG. Scale bars at $100 \mu \mathrm{m}$. (D and E) The hematoxylin/eosin stained sections of the ovaries from PD0325901-treated mice. In response to the LH surge, granulosa cells adjacent to the basement membrane inside the distended unruptured follicle underwent luteinization (large mesenchymal cells arrowheads) and neovascularization (arrows) in both vehicle $(\mathrm{CL})$ and PD0325901-treated (unovulated follicle) mice. Scale bars at 100 $\mu \mathrm{m}$. (F) Expression of steroidogenesis-related protein Star was unaltered in mice treated with PD0325901 at $4 \mathrm{~h}$ after hCG. Ovaries were collected at $18 \mathrm{~h}$ after hCG. (G) Star protein abundance was similar in both vehicle- and PD0325901-treated mice $(P>0.05)$.
Further, observation at higher magnification revealed that the unruptured ovulatory-sized follicles in vehicleand PD0325901-treated mice appeared to have undergone luteinization as evidenced by granulosa cells showing morphological features of luteal cells (Fig. 2D and $\mathrm{E}$ ). There was also evidence of neovascularization as indicated by the presence of numerous capillaries containing red blood cells among granulosa cells within unruptured ovulatory-sized follicles in vehicle- and PD0325901-treated mice (Fig. 2D and E). Immunoblot analysis of ovaries from PD0325901-treated mice collected at $18 \mathrm{~h}$ post-hCG revealed similar levels of Star protein compared to those of vehicle-treated mice even though inhibitor-treated mice had markedly fewer ovulations (Fig. 2F and G).

\section{Expression profile of RSK isoforms in granulosa cells}

It was reported that RSK3 is one of the ERK1/2 targets that is induced by the LH surge in granulosa cells of ovulating follicles (Fan et al. 2009). Therefore, we wanted to test if RSK3, as a mediator of continued ERK1/2 signaling, plays a role in the mouse ovary. First, we determined the expression pattern of all four RSK isoforms in granulosa and luteal cells collected at specific stages of gonadotropin stimulated follicular and luteal growth. The mRNA abundance of Rps6ka2 (RSK3) remained unchanged through eCG-induced follicular growth, but its levels were higher by about five-fold at $4 \mathrm{~h}$ post-hCG compared to $48 \mathrm{~h}$ post-eCG $(P<0.003$, Fig. 3$)$. The levels of RSK3 mRNA remained high at 7 and $12 \mathrm{~h}$ post- 


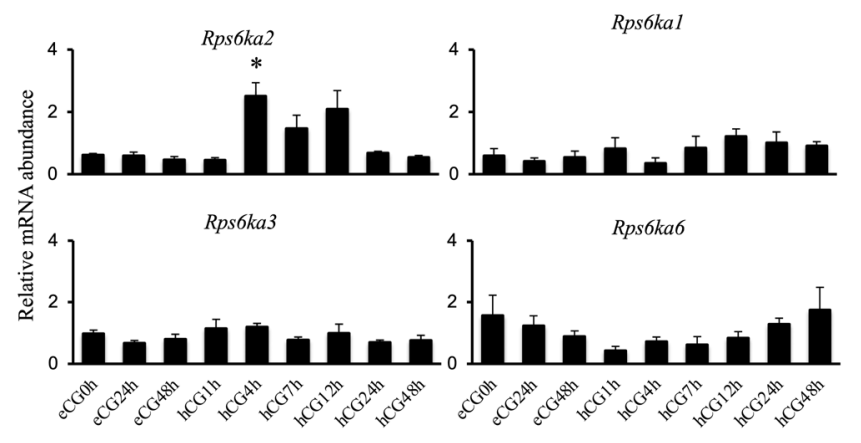

Figure 3 RSK3 is dramatically induced by hCG treatment. Relative mRNA levels of Rps6ka2, Rps6ka1, Rps6ka3 and Rps6ka6 in granulosa and luteal cells collected at different time points of superovulation ( $n=5$ per time-point) from murine ovaries. Data are expressed as a mean \pm S.E.M. ${ }^{* *} P<0.01$.

hCG and returned to baseline by $24 \mathrm{~h}$ post-hCG. On the contrary, there were no significant changes in Rps6ka1 (RSK1), Rps6ka3 (RSK2) and Rps6ka6 (RSK4) transcript abundance through follicular and luteal development $(P>0.05$; Fig. 3).

\section{Ovulation rate and fertility of RSK3-/- mice}

Based on unique hCG-induced expression of Rps6ka2, we hypothesized that RSK3 may play a significant role in ovulation in mice. We used the recently developed RSK3 knockout mice (RSK3-/-) (Li et al. 2013) to investigate the potential role of RSK3 in ovulation and fertility. First, we examined the expression of RSK3 in granulosa cells at peak expression time-point, $4 \mathrm{~h}$ posthCG. As expected, transcript abundance of Rps6ka2 was 13 -fold lower in RSK3-/- granulosa cells compared to $\mathrm{RSK} 3+/+$ granulosa cells $(P<0.01$, Fig. $4 \mathrm{~A})$. On the contrary, mRNA levels of Rps6ka1, Rps6ka3 and Rps6ka6 genes were similar between granulosa cells of both genotypes (data not shown) demonstrating that there was no compensatory expression of other RSK isoforms.

As part of reproductive phenotyping, we first examined the superovulatory response in immature RSK3-/- and RSK3+/+ mice. Ovulation rate in response to superovulation treatment was about $80 \%$ lower in RSK3 $-/-$ than RSK3+/+ mice ( $P<0.01$; Fig. $4 \mathrm{~B})$. We then examined the ovulation rate in adult RSK3-knockout and WT mice. Ovulation rate, as measured by the number of oocytes in the oviducts on the day of vaginal plug, was about $40 \%$ lower in RSK3-/- than RSK3+/+ mice $(P<0.05$; Fig. 4C). In line with this aberrant ovulatory phenotype, breeding trials revealed that RSK3-/- mice were sub-fertile with smaller litter size than RSK3+/+ mice $(P<0.05$; Fig. 4D).
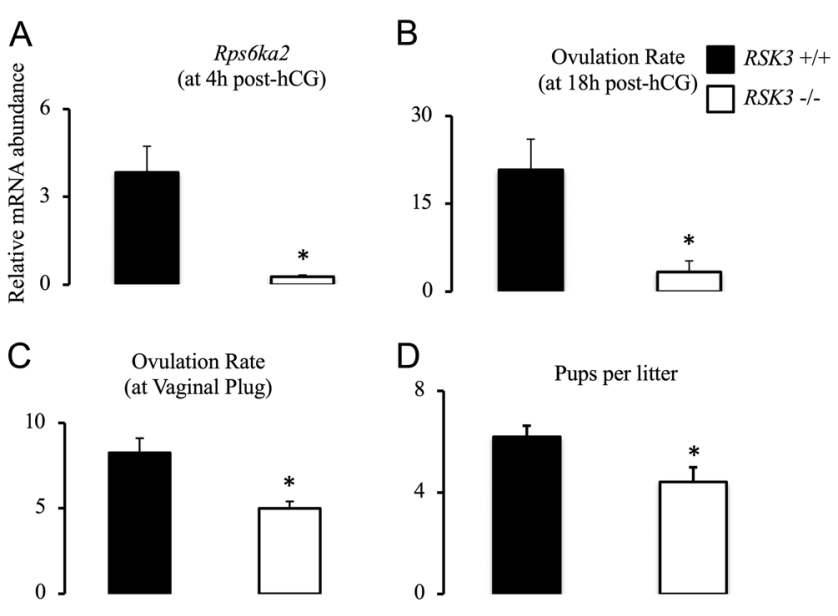

Figure 4 Reproductive phenotype of $R S K 3-/-$ mice. (A) Relative mRNA levels of Rps6ka2 in granulosa cells from $R S K 3+/+$ and $R S K 3-/-$ mice ( $n=3$ per genotype) collected at $4 \mathrm{~h}$ post-hCG. Data are expressed as a mean \pm S.E.M. ${ }^{*} P<0.05$. (B and C) $R S K 3+/+$ and RSK3-/- mice have different ovulation rates. Ovulation rate was established by counting the number of oocytes in the oviducts of superovulated mice wild-type $(n=5)$ mice and RSK3-knockout $(n=6)$ mice 18 h-post hCG administration. (D) Litter sizes from wild-type mice $(n=4)$ and RSK3-knockout mice $(n=4)$ were averaged among litters per mouse over a 6-month breeding trial. Data are expressed as mean \pm S.E.M. from both genotyped groups. ${ }^{*} P<0.05$ and ${ }^{* *} P<0.01$.

\section{PD0325901 treatment at $4 \mathrm{~h}$ post-hCG results in aberrant expression of genes involved in tissue remodeling and leukocyte infiltration in ovulating follicles}

Data from both pharmacological and genetic models showed that lack of ERK1/2 signaling beyond 4 $h$ post-hCG results in defective follicular rupture. We sought to define the molecular determinants of this deficient follicular rupture. We chose to use a pharmacological inhibition model for two reasons. First, the pharmacological model allows us to inhibit ERK $1 / 2$ signals at a precise time point during the ovulatory process. Second, the pharmacological model would inhibit all downstream mediators of ERK $1 / 2$ signals resulting in robust anovulatory phenotype, whereas subfertile RSK3-/- mice lacked one of the many ERK1/2 mediators.

Our initial qPCR analyses of RNA from granulosa cells collected from the whole ovaries at $8 \mathrm{~h}$ post-hCG showed mostly non-significant differences in transcript abundance between vehicle- and PD0325901-treated mice (data not shown). We reasoned that this may be because collection of granulosa cells from the whole ovary may not enrich the small number of cells with gene expression differences localized to a small area of the ovulatory follicle. For that reason, we chose to isolate two ovulatory follicles per mouse (one per ovary) and 


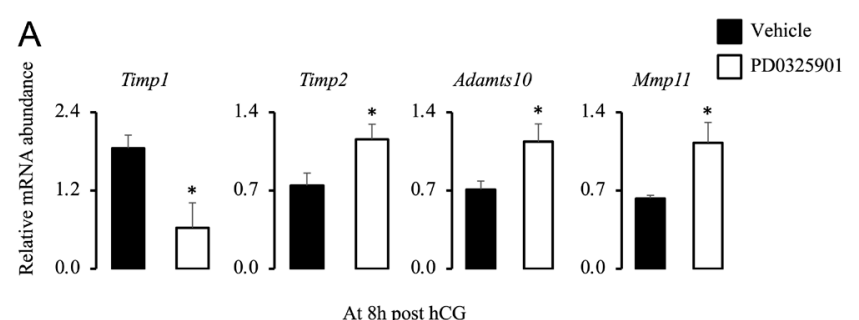

B
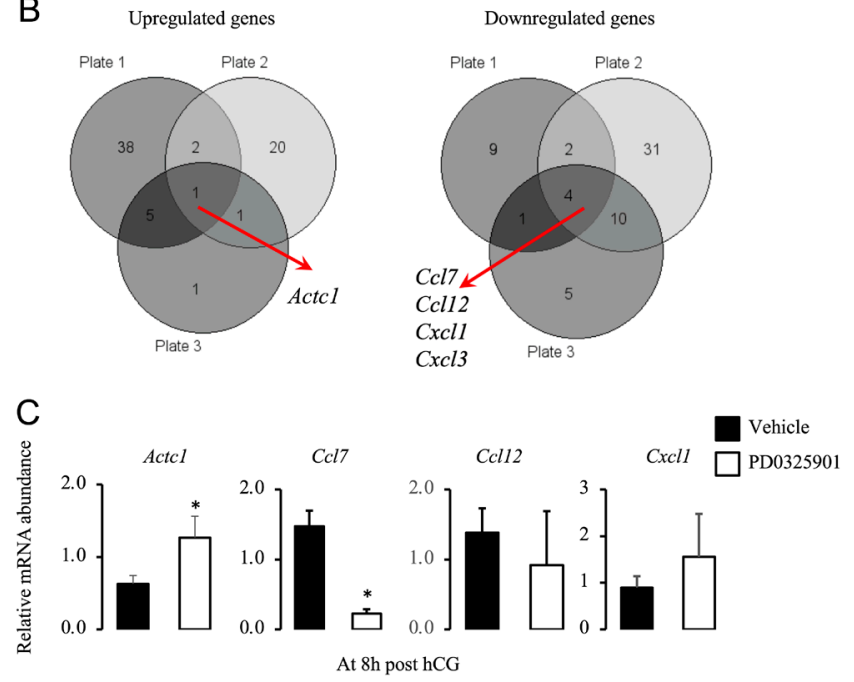

Figure 5 Inhibition of ERK1/2 at $4 \mathrm{~h}$ post-hCG results in abnormal expression of genes associated with extracellular matrix degradation and leukocyte infiltration. (A) Gene expression of Timp1, Timp2, Adamts 10 and Mmp 11 was measured in granulosa cells collected by follicular puncture at $8 \mathrm{~h}$ post-hCG with or without inhibition of ERK $1 / 2$ at $4 \mathrm{~h}$ hCG ( $n=4$ per group). Data are expressed as a mean \pm S.E.M. ${ }^{*} P<0.05$. (B) Number of upregulated and downregulated genes in the PCR arrays using the RNA purified from isolated ovulating follicles (details in 'Methods' section) at $8 \mathrm{~h}$ post-hCG from separate mice treated with or without the inhibitor of ERK $1 / 2$ at $4 \mathrm{~h}$ hCG ( $n=2$ follicles per mouse per group in each array plate). Up and downregulated genes in ERK1/2-inhibition group relative to vehicle group were identified using the algorithm provided by the manufacturer. (C) Relative mRNA levels of Actc1, Ccl7, Ccl12 and $\mathrm{CxCl} 1$ in granulosa cells collected at $8 \mathrm{~h}$ hCG with or without inhibition of ERK1/2 at $4 \mathrm{~h}$ hCG ( $n=4$ per group). Data are expressed as a mean \pm S.E.M. ${ }^{*} P<0.05$.

purify RNA from the whole follicles. Even though this method would yield a mixture of granulosa, theca and oocytes, it is still a better option to obtain an enriched population of cells expressing genes involved in follicle rupture.

First, we examined the transcript abundance of the genes involved in extracellular matrix remodeling during ovulation in ovulating follicles of vehicle- and inhibitory-treated mice (Duffy et al. 2019). There were higher levels of Timp2, Adamts10, and Mmp11, but lower level of Timp1 at $8 \mathrm{~h}$ post-hCG in ovulating follicles of PD0325901 treated than those of vehicletreated mice (Fig. 5A). With this observation of imbalance in the expression of the extracellular matrix proteases and their inhibitors, we sought to identify other dysregulated genes involved in tissue remodeling and leukocyte infiltration associated with follicular rupture (Oakley et al. 2010). We used a PCR-array to identify differentially expressed genes between vehicle- and PD0325901-treated follicles. The results of PCR-arrays were highly variable potentially due to mixture of different follicular cell types undergoing dramatically divergent differentiation. The number of up and downregulated genes varied from 8-46 and 16-47, respectively, among the three replicates using follicular samples from separate groups of mice. Upon comparing the three replicates, we found one upregulated gene (Actc1) and four downregulated genes (Ccl7, Ccl12, $\mathrm{CxCl} 1$ and $\mathrm{CxCl} 3$ ) common for the three array replicates (Fig. 5B). Of these, we were able to confirm higher levels of Actc 1 and lower levels of $\mathrm{Ccl} 7$ transcripts in ovulating follicles of PD0325901 treated than those of vehicle-treated mice (Fig. 5C).

\section{Discussion}

In the present study, inhibition of ERK $1 / 2$ activity at 4 $\mathrm{h}$ after hCG stimulation disrupted follicular rupture without altering cumulus expansion and oocyte meiotic maturation. As ovulation is supposed to occur around $12 \mathrm{~h}$ post-hCG stimulus in immature superstimulated mice and we explored the oviduct for ovulated oocytes at 18-24 h after hCG stimulus, it is unlikely that follicle rupture was delayed in inhibitor-treated mice. Reduced ovulation rate due to ERK1/2 inhibition in our current model is different from previous studies (Fan et al. 2009, Siddappa et al. 2015), which demonstrated anovulation due to lack of LH-induced ERK1/2 activity. In those studies, ERK1/2 signals were absent right from the beginning of the ovulatory process. Whereas in the present study, initial ERK1/2 activity was not affected as the inhibitor was administered only at $4 \mathrm{~h}$ after hCG treatment. Like those previous studies, there were large distended unruptured preovulatory follicles in ovaries of mice with ERK1/2 inhibition at $4 \mathrm{~h}$ hCG. However, contrary to those previous studies, histological observations showed that trapped oocytes within the unruptured follicles from PD0325901-treated mice in this study appeared meiotically mature with normally expanded cumulus. Further, the oocytes ovulated in PD0325901-treated mice were meiotically mature as observed in ovulated oocytes of vehicle-treated mice. These observations are consistent with the fact that cumulus expansion and oocyte meiotic resumption would have started by $4 \mathrm{~h}$ post-hCG when the inhibitor was administered. Indeed, genes critical for meiotic resumption and cumulus expansion such as Has2, Areg, Ereg, Ptx 3 and others are all highly expressed, by $4 \mathrm{~h}$ post-hCG in mice (Fan et al. 2009, Wigglesworth et al. 2015, Robker et al. 2018).

Another important contrast between this study and the previous studies (Fan et al. 2009, Siddappa 
et al. 2015) with ERK1/2 signal abrogation from the beginning of the ovulatory process is luteinization. In both previous studies, abolition of ERK $1 / 2$ signal at the time of hCG treatment resulted in dramatically reduced expression of Star and complete absence of epithelialto-mesenchymal transition, which is the hallmark of luteinization (Irving-Rodgers et al. 2004). In this study, we found that although the follicles that ovulated formed corpus luteum, the granulosa cells of large unovulated follicles had mesenchymal morphology of luteal cells along with blood vessels as observed in corpora lutea of vehicle-treated mice. This was supported by the fact that Star levels were similar in the ovaries of both vehicleand PD0325901-treated mice. In addition, the presence of blood-filled capillaries among granulosa cells indicated that the luteinization process was underway (Murphy 2000). Since the marker of luteinization, Star as well as the driver of neovascularization, Vegfa are induced by immediate-early transcription factors such as Cebpa/b (Sterneck et al. 1997, Fan et al. 2011), Nr5a2 (Duggavathi et al. 2008) and Hif1/2 (Kim et al. 2009), it is possible that inhibition of ERK1/2 after their activation does not impact luteinization and angiogenesis. In line with this, intra luteal infusion of another ERK $1 / 2$ inhibitor PD98059 in bonnet monkeys on day 9 of luteal phase (period of high functioning corpus luteum), did not affect STAR mRNA levels and circulating progesterone concentration (Yadav \& Medhamurthy 2006). All these observations indicate that ERK1/2 signals beyond $4 \mathrm{~h}$ post-hCG may not be necessary for luteinization and cumulus expansion.

Our data showed a dramatic induction of RSK3 in granulosa cells of ovulating follicles indicating that ERK1/2 signals are sustained beyond $4 \mathrm{~h}$ and may play a role during mouse ovulation. Confirming this hypothesis, RSK3-/- showed reduced ovulation rate both in adult and superovulated immature mice, and they were sub-fertile. These data clearly demonstrate that RSK3, one of the many ERK1/2 signal mediators, is important for ovulation. As it was shown that RSK3 in the oocyte is not necessary for maturation and meiotic progression (Dumont et al. 2005) it is likely that infertility in RSK3-/- mice is due to molecular defects in other cell types in ovulating follicles. Also, RSK3 is one of the many mediators of ERK $1 / 2$ signaling and thus, the reduction in ovulation rate appeared to not be as robust as that seen in PD0325901-treated mice (that have complete inhibition of the ERK $1 / 2$ pathway and potentially all its mediators). Taken together, data from both pharmacological and genetic models demonstrate that ERK $1 / 2$ signals beyond $4 \mathrm{~h}$ post-hCG are needed for follicular rupture.

While most parts of the ovulating follicle are undergoing luteinization and angiogenesis, a small region in the follicular wall toward the ovarian surface undergoes a separate set of morphological changes (reviewed in Duffy et al. 2019). These unique regional changes lead to breaching of the follicular wall so that the COCs will be released into oviduct. This regionspecific regulation of cellular differentiation and extracellular matrix remodeling has been a barrier to studying molecular mechanisms regulating follicular rupture. There have been several studies proposing various cytokines, cell types (granulosa, theca and leukocytes) and tissue remodeling enzymes involved in the ovulatory processes of angiogenesis, cell motility and follicular rupture. At the time of follicular rupture, proteinases degrade extracellular matrix and connective tissues at the apex of follicle in a circumferential manner (Russell \& Robker 2007). Important proteinases involved in the proteolysis of the extracellular matrix during follicular rupture include matrix metalloproteinases (MMPs), serine proteinases (Plasminogen activators and plasmin), a disintegrin and metalloproteinase domain with thrombospondin motifs (ADAMTSs) and cathepsin L (Ohnishi et al. 2005). Tissue inhibitors of metalloproteinases (TIMPs) regulate proteolytic activities of MMPs and a ratio in favor of MMP activity results in ECM degradation, whereas a ratio in favor of TIMP inhibits ECM degradation (Mclntush \& Smith 1998). Among the tissue remodeling enzymes, TIMPs play contrasting roles because of their ability to regulate membrane-bound and secreted MMPs. For example, while TIMP2 inhibits MMP2 by direct binding in extracellular space, TIMP2 also participates in the activation of MMP2 through membrane-bound MMP14 (Wang et al. 2000, Jezierska \& Motyl 2009). These data demonstrate that both higher and lower expression of TIMPs can have negative impact on the activity of MMPs. Thus, a balanced expression of various tissue remodeling enzymes is necessary for normal follicular rupture. Our data of lower Timp1 and higher Timp2 demonstrate such an imbalance of TIMPs in ovulatory follicles of PD0325901-treated mice. Supporting this, it has been reported that presence of excessive TIMP2 can inhibit MMP14 activity and decrease the processing of proMMP2 to active MMP2 in BS-C-1 cells (HernandezBarrantes et al. 2000, Bernardo \& Fridman 2003). Further, our data of abnormal expression of Adamts 10 and Mmp11 are consistent with dysregulated matrix protease machinery in ovulating follicles in which ERK1/2 signaling was inhibited at $4 \mathrm{~h}$ post-hCG. This imbalance in matrix proteases and their inhibitors may have resulted in inefficient proteolysis of the extracellular matrix, which is required for normal follicular rupture.

While the data presented here provide compelling evidence for the role of ERK $1 / 2$ in gene expression pattern of granulosa cells within ovulating follicles, the limitations of the methods used in this study need to be considered. The LH surge regulates ovulation through exquisitely orchestrated sequential gene expression programs within somatic cells of follicles, namely granulosa and theca cells. Also, the morphological and biochemical changes in these cells differ depending on their location within 
Proposed model for follicular rupture
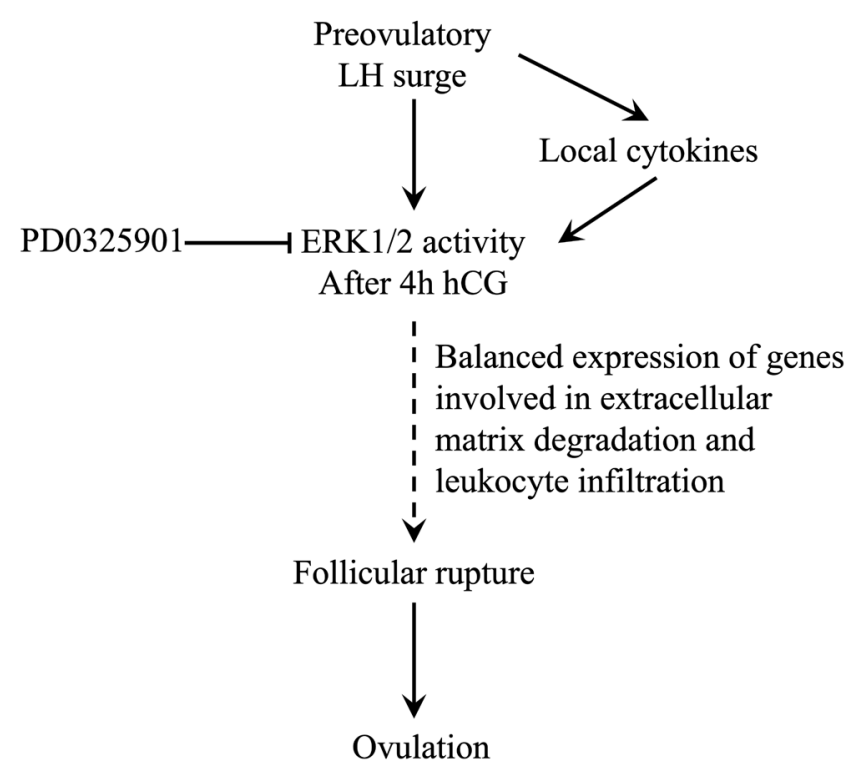

Figure 6 Proposed mechanism for ERK1/2 regulation of follicular rupture.

the ovulating follicle (Duffy et al. 2019). To achieve concomitant but divergent processes of ovulation, the cells at the apex express genes necessary for the breach of the wall and those at the interior wall express genes involved in cell motility, neo-vascularization and luteinization. As technologies to specifically inactivate ERK1/2 signals in a small groups of granulosa cells (e.g. those at the apex) of ovulating follicles are not currently available, we have used a pharmacological inhibitor that abolishes any active ERK $1 / 2$ signals in all cell types of the ovary. It is plausible that the gene expression deficiencies in response to comprehensive inhibition of ERK $1 / 2$ signaling in all cell types is due to the direct consequence of abrogated ERK $1 / 2$ signals within granulosa cells or due to indirect effects of the abnormal cell-to-cell interactions because of ERK $1 / 2$ inhibition in theca or other cells. Nonetheless, as the most enriched cell type obtained by follicular puncture, our data are indicative of the aberrant gene expression within granulosa cells. Fortunately, the emerging technologies of single-cell RNA sequencing and quantitative in situ hybridization can delineate gene expression patterns of cell types at different locations within ovulating follicles. Like ERK1/2 genes, RSK3 is expected to be expressed in most cell types. There are no currently available antibodies for immunoblots or immunohistochemistry to quantify its protein levels. However, our qPCR data demonstrate that it is definitely expressed in granulosa cells, thus, it is possible to infer that abnormal ovulation in these mice is due, at least in part, to absence of RSK3 in granulosa cells. Most importantly, the imbalance of extracellular matrix modulators is demonstrated by quantitative gene expression data. This observation needs to be further supported by altered proteolytic activity or altered extracellular matrix composition. Unfortunately, teasing apart location-specific protease activity and matrix composition are not possible with currently available technologies.

In conclusion, our data from both pharmacological and genetic models demonstrate that lack of ERK1/2 during ovulation results in abnormal follicular rupture. Specifically, our pharmacological inhibition of ERK1/2 at $4 \mathrm{~h}$ post-hCG reduced the rate of follicular rupture without affecting luteinization, oocyte meiosis and cumulus expansion. Our molecular phenotyping indicates that sustained ERK1/2 signals play a critical role in the balanced expression of genes involved in extracellular matrix degradation and leukocyte infiltration necessary for successful follicular rupture (Fig. 6). Finally, this pharmacological method of separation of follicular rupture from luteinization and oocyte maturation offers an excellent experimental model to study molecular mechanisms of divergent tissue remodeling processes associated with luteinization and follicular rupture (Duffy et al. 2019).

\section{Supplementary materials}

This is linked to the online version of the paper at https://do i.org/10.1530/REP-20-0087.

\section{Declaration of interest}

The authors declare that there is no conflict of interest that could be perceived as prejudicing the impartiality of the research reported.

\section{Funding}

This work was partly funded by the National Science and Engineering Research Council (NSERC) of Canada (RGPIN371850 and RGPIN-2019-06667 to R D, and RGPIN-201704736 to P P R). This work was also supported by grants from the Canadian Institutes for Health Research (CIHR; MOP142374 to $\mathrm{P} P \mathrm{R})$. E M was funded by NSERC-CREATE and McGill Graduate Excellence Fellowship. D $S$ was funded by McGill Graduate Student Fellowship, Department of Animal Science, Graduate Excellence Fellowship and RQR. Y S was funded by RQR-CREATE and McGill Graduate Excellence Fellowship. P P R is a senior scholar of the Fonds de la Recherche du Québec - Santé (FRQS).

\section{Author contribution statement}

E M designed experiments, collected and processed samples, analyzed and interpreted data, prepared figures and wrote manuscript. D S and Y S contributed to ideas, designed experiments, collected and processed samples, interpreted data 
and reviewed the manuscript. P P R performed reproductive phenotyping of RSK3 mice and reviewed the manuscript and $\mathrm{V}$ B performed analyses of oocyte maturation, contributed to experimental design and reviewed the manuscript. $\mathrm{R} D$ conceived the study, designed experiments, analyzed and interpreted data, and edited the manuscript. Y S and D S contributed equally to this work.

\section{Acknowledgements}

The authors would like to thank Rodrigo Bohrer for his invaluable assistance, as well as Kim Lévesque for expert technical help with animal work. The authors also thank Professors Sarah Kimmins, Jaswinder Singh and Luis Agellon for allowing us to use their laboratory facilities for this study.

\section{References}

Adriaenssens T, Wathlet S, Segers I, Verheyen G, De Vos A, Van der Elst J, Coucke W, Devroey P \& Smitz J 2010 Cumulus cell gene expression is associated with oocyte developmental quality and influenced by patient and treatment characteristics. Human Reproduction 25 1259-1270. (https://doi.org/10.1093/humrep/deq049)

Anjum R \& Blenis J 2008 The RSK family of kinases: emerging roles in cellular signalling. Nature Reviews: Molecular Cell Biology 9 747-758. (https://doi.org/10.1038/nrm2509)

Ashkenazi H, Cao X, Motola S, Popliker M, Conti M \& Tsafriri A 2005 Epidermal growth factor family members: endogenous mediators of the ovulatory response. Endocrinology 146 77-84. (https://doi.org/10.1210/ en.2004-0588)

Ben-Ami I, Armon L, Freimann S, Strassburger D, Ron-El R \& Amsterdam A 2009 EGF-like growth factors as LH mediators in the human corpus luteum. Human Reproduction 24 176-184. (https://doi.org/10.1093/ humrep/den359)

Bernardo MM \& Fridman R 2003 TIMP-2 (tissue inhibitor of metalloproteinase-2) regulates MMP-2 (matrix metalloproteinase-2) activity in the extracellular environment after pro-MMP-2 activation by MT1 (membrane type 1)-MMP. Biochemical Journal 374 739-745. (https://doi.org/10.1042/BJ20030557)

Duffy DM, Ko C, Jo M, Brannstrom M \& Curry TE 2019 Ovulation: parallels with inflammatory processes. Endocrine Reviews 40 369-416. (https://doi.org/10.1210/er.2018-00075)

Duggavathi R, Volle DH, Mataki C, Antal MC, Messaddeq N, Auwerx J, Murphy BD \& Schoonjans K 2008 Liver receptor homolog 1 is essential for ovulation. Genes and Development 22 1871-1876. (https://doi. org/10.1101/gad.472008)

Duggavathi R, Siddappa D, Schuermann Y, Pansera M, Menard IJ, Praslickova D \& Agellon LB 2015 The fatty acid binding protein 6 gene (Fabp6) is expressed in murine granulosa cells and is involved in ovulatory response to superstimulation. Journal of Reproduction and Development 61 237-240. (https://doi.org/10.1262/jrd.2014-139)

Dumont J, Umbhauer M, Rassinier P, Hanauer A \& Verlhac MH 2005 p90Rsk is not involved in cytostatic factor arrest in mouse oocytes. Journal of Cell Biology 169 227-231. (https://doi.org/10.1083/jcb.200501027)

Dupuis L, Schuermann Y, Cohen T, Siddappa D, Kalaiselvanraja A, Pansera M, Bordignon V \& Duggavathi R 2014 Role of leptin receptors in granulosa cells during ovulation. Reproduction 147 221-229. (https:// doi.org/10.1530/REP-13-0356)

Fan HY, Shimada M, Liu Z, Cahill N, Noma N, Wu Y, Gossen J \& Richards JS 2008 Selective expression of KrasG12D in granulosa cells of the mouse ovary causes defects in follicle development and ovulation. Development 135 2127-2137. (https://doi.org/10.1242/dev.020560)

Fan HY, Liu Z, Shimada M, Sterneck E, Johnson PF, Hedrick SM \& Richards JS 2009 MAPK3/1 (ERK1/2) in ovarian granulosa cells are essential for female fertility. Science 324 938-941. (https://doi. org/10.1126/science.1171396)

Fan HY, Liu Z, Johnson PF \& Richards JS 2011 CCAAT/enhancer-binding proteins (C/EBP)-alpha and -beta are essential for ovulation, luteinization, and the expression of key target genes. Molecular Endocrinology 25 253-268. (https://doi.org/10.1210/me.2010-0318)

Henderson YC, Chen Y, Frederick MJ, Lai SY \& Clayman GL 2010 MEK inhibitor PD0325901 significantly reduces the growth of papillary thyroid carcinoma cells in vitro and in vivo. Molecular Cancer Therapeutics 9 1968-1976. (https://doi.org/10.1158/1535-7163.MCT10-0062)

Hernandez-Barrantes S, Toth M, Bernardo MM, Yurkova M, Gervasi DC, Raz Y, Sang QA \& Fridman R 2000 Binding of active (57 kDa) membrane type 1-matrix metalloproteinase (MT1-MMP) to tissue inhibitor of metalloproteinase (TIMP)-2 regulates MT1-MMP processing and proMMP-2 activation. Journal of Biological Chemistry 275 12080-12089. (https://doi.org/10.1074/jbc.275.16.12080)

Irving-Rodgers HF, Harland ML \& Rodgers RJ 2004 A novel basal lamina matrix of the stratified epithelium of the ovarian follicle. Matrix Biology 23 207-217. (https://doi.org/10.1016/j.matbio.2004.05.008)

Jezierska A \& Motyl T 2009 Matrix metalloproteinase-2 involvement in breast cancer progression: a mini-review. Medical Science Monitor 15 RA32-RA40.

Kim M, Lee JH, Koh H, Lee SY, Jang C, Chung CJ, Sung JH, Blenis J \& Chung J 2006 Inhibition of ERK-MAP kinase signaling by RSK during Drosophila development. EMBO Journal 25 3056-3067. (https://doi. org/10.1038/sj.emboj.7601180)

Kim J, Bagchi IC \& Bagchi MK 2009 Signaling by hypoxia-inducible factors is critical for ovulation in mice. Endocrinology 150 3392-3400. (https:// doi.org/10.1210/en.2008-0948)

Li J, Kritzer MD, Michel JJ, Le A, Thakur H, Gayanilo M, Passariello CL, Negro A, Danial JB, Oskouei B et al. 2013 Anchored p90 ribosomal S6 kinase 3 is required for cardiac myocyte hypertrophy. Circulation Research 112 128-139. (https://doi.org/10.1161/CIRCRESAHA.112.276162)

McIntush EW \& Smith MF 1998 Matrix metalloproteinases and tissue inhibitors of metalloproteinases in ovarian function. Reviews of Reproduction 3 23-30. (https://doi.org/10.1530/ror.0.0030023)

Murphy BD 2000 Models of luteinization. Biology of Reproduction 63 2-11. (https://doi.org/10.1095/biolreprod63.1.2)

Oakley OR, Kim H, El-Amouri I, Lin PC, Cho J, Bani-Ahmad M \& Ko C 2010 Periovulatory leukocyte infiltration in the rat ovary. Endocrinology 151 4551-4559. (https://doi.org/10.1210/en.2009-1444)

Ohnishi J, Ohnishi E, Shibuya H \& Takahashi T 2005 Functions for proteinases in the ovulatory process. Biochimica et Biophysica Acta 1751 95-109. (https://doi.org/10.1016/j.bbapap.2005.05.002)

Park JY, Su YQ, Ariga M, Law E, Jin SL \& Conti M 2004 EGF-like growth factors as mediators of $\mathrm{LH}$ action in the ovulatory follicle. Science $\mathbf{3 0 3}$ 682-684. (https://doi.org/10.1126/science.1092463)

Richards JS 2005 Ovulation: new factors that prepare the oocyte for fertilization. Molecular and Cellular Endocrinology 234 75-79. (https:// doi.org/10.1016/j.mce.2005.01.004)

Richards JS, Russell DL, Ochsner S \& Espey LL 2002 Ovulation: new dimensions and new regulators of the inflammatory-like response. Annual Review of Physiology 64 69-92. (https://doi.org/10.1146/ annurev.physiol.64.081501.131029)

Robker RL, Hennebold JD \& Russell DL 2018 Coordination of ovulation and oocyte maturation: a good egg at the right time. Endocrinology 159 3209-3218. (https://doi.org/10.1210/en.2018-00485)

Russell DL \& Robker RL 2007 Molecular mechanisms of ovulation: coordination through the cumulus complex. Human Reproduction Update 13 289-312. (https://doi.org/10.1093/humupd/dml062)

Siddappa D, Beaulieu É, Gevry N, Roux PP, Bordignon V \& Duggavathi R 2015 Effect of the transient pharmacological inhibition of Mapk3/1 pathway on ovulation in mice. PLOS ONE 10 e0119387. (https://doi. org/10.1371/journal.pone.0119387)

Sterneck E, Tessarollo L \& Johnson PF 1997 An essential role for C/EBPbeta in female reproduction. Genes and Development 11 2153-2162. (https://doi.org/10.1101/gad.11.17.2153) 
Wang Z, Juttermann R \& Soloway PD 2000 TIMP-2 is required for efficient activation of proMMP-2 in vivo. Journal of Biological Chemistry 275 26411-26415. (https://doi.org/10.1074/jbc.M001270200)

Wigglesworth K, Lee KB, Emori C, Sugiura K \& Eppig JJ 2015 Transcriptomic diversification of developing cumulus and mural granulosa cells in mouse ovarian follicles. Biology of Reproduction 92 23. (https://doi. org/10.1095/biolreprod.114.121756)

Yadav VK \& Medhamurthy R 2006 Dynamic changes in mitogen-activated protein kinase (MAPK) activities in the corpus luteum of the bonnet monkey (Macaca radiata) during development, induced luteolysis, and simulated early pregnancy: a role for p38 MAPK in the regulation of luteal function. Endocrinology 147 2018-2027. (https://doi.org/10.1210/ en.2005-1372)

Received 12 February 2020

First decision 26 March 2020

Revised Manuscript received 13 November 2020

Accepted 24 December 2020 